\title{
Kainszeichen, Keniter und Beschneidung.
}

Seitdem der Herausgeber dieser Zeitschrift seinen Artikel "Das Kainszeichen" schrieb (ZAW XIV S. 250 ff.), habe ich mir öfters die Frage vorgelegt: Kann dieses Zeichen, anstatt einer Tätowierung oder einer Haartracht, nicht die Beschneidung gewesen sein?

In I Mos. 4, I und 4, I 7 ff. haben wir die alte Quelle J ${ }^{\mathrm{x}}$

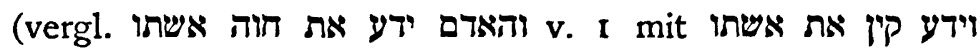
v. 17). Was dazwischen steht ist die jüngere Arbeit des $\mathrm{J}^{3}$ (4, 2-16), mit ihrem (v. I5) an (v. I) des Jx sich anknüpfend.

Eva sagt: קניתי איש את יהוה (v. I). Was ist הת? So lange man daraus die Präposition des Accusativus $\Omega$ lesen will, bleibt doch die Exegese ein rechter Notschuss. Warum sollen wir nicht sis) lesen? Das giebt einen sehr guten Sinn: „Ich habe bekommen den Mann des Jahwezeichens". (אנשי מופת, איש אות, vergl. Sach. 3, 8; und für die Genetive: I Mos. 47, 9; Jes. I0, I2;

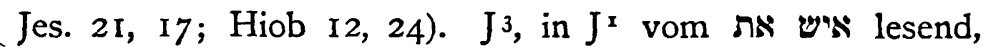
fühlte sich veranlasst, näher $\mathrm{zu}$ erklären, wie Kain das Zeichen bekommen hatte, und giebt in I Mos. 4, 2-16 symbolischer Weise ein Stücklein Kenitergeschichte.

In Israel hat es eine Tradition gegeben, dass Mose's Schwiegervater ein Keniter gewesen sei, welche Überlieferung 
wir in der deuteronomistischen Überarbeitung von Richt I, 16 und 4, I I bewahrt finden. Und Jx berichtet, dass Mose's Frau Zippora in Mose's Geschlecht die Beschneidung eingeführt hat (2 Mos. 4, 24-25). Die Beschneidung war, nach $\mathrm{J}^{\mathrm{x}}$, bei den Kenitern, bereits bevor Israel sie annahm, etwas zum Jahwehdienste gehöriges, ein schützendes Zeichen. Und das Zeichen, das, nach J3, ישם יהוה לקין (I Mos. 4, I5), muss doch etwas gewesen sein, das Kain überall mittrug, sollte es ein Schutzmittel sein.

Bei seiner Interpolation (I Mos. 4, 2-I6) - denn J3 ist wahrscheinlich Redaktor von $\mathrm{J}^{x}$ und $\mathrm{J}^{2}-$ übersieht er aber, dass $\mathrm{J}^{\mathrm{x}}$ die Beschneidung beim Kainstamme für älter hält als die Ereignisse, die er in seiner Erklärung des Kainzeichens als Brudermord charakterisiert.

Dieses Mordes wegen lässt $\mathrm{J}^{3}$ Kain vom Ackerlande und von Jahweh's Heiligtümern (מעל פני אדמה ומפניך, I Mos. $4,14^{\text {a) }}$ vertrieben werden, um hinfort als Nomade in dem Lande, unbebaut und bebaut, umherzuziehen (נע ונד בארץ) I Mos. 4, 16b). Seine neue Wohnstätte heisst das Land des Umherschweifens (ארץ נוד, I Mos. 4, I6); das ist, meines Erachtens, das Negeb zwischen Juda und Edom. (Eine Glosse des $\mathrm{R}$, um $\mathrm{J}^{3}$ besser an $\mathrm{J}^{\mathrm{x}}$ anzuknüpfen, ist gewiss (קדמת עדן

In der Zeit Barak's und Debora's treffen wir Keniter ansässig in der Ebene des Kison. Die ältere Siseraüberlieferung lässt sie in Zeltdörfern wohnen unweit von Harôsethhaggojîm (heute Harôthije, am linken Ufer des Kisonbaches) und vom Tabôr (Richt. 4, 16-17). (Vergl. die HawwôthJa'îr, die in Gilead immer in einer bestimmten Gegend ihre Plätze eingenommen haben.)

Die jüngere Jabinüberlieferung dagegen stellt sie viel nördlicher, bei Jabin's Hauptstadt Kedes, und lässt Heber sich von den übrigen Kenitern getrennt haben. Das ist 
einfach um eine so nördliche Stellung eines Keniterclans zu erklären (Richt. 4, II, wo מבני חבב חתן משה kennbar vom deuteronomistischen Redaktor des Richterbuches ist).

Die glaubwürdigste Úberlieferung ist natürlich die ältere Siseratradition, weil bezüglich Heber's Wohnplatz und Schlachtfeld mit dem sehr alten Deboraliede völlig übereinstimmend (vergl. Richt. 5, 19. 21 : מישון תענד, מגדו).

In Saul's Tagen und später treffen wir die Keniter im Negeb an (I Sam. I 5, 6); also in den Steppen, weit vom Ackerlande (אדמה) der Kisonebene.

Die Erzählung des J3 vom Brudermorde in I Mos. 4 giebt uns vielleicht den Schlüssel des Rätsels in die Hand. Die mit den erst in Kanaan eingedrungenen israelitischen Stämmen mitgekommenen Keniter sollen sich am Kison angesiedelt und da noch in den Tagen des Barak Ackerbau betrieben haben. Aber kurz darauf haben sie gewiss etwas scheussliches betrieben, wovon der Mord Abel's bei $\mathrm{J}^{3}$ das Symbol ist. Sie wurden deshalb verjagt, und ihre grössere Mehrzahl floh durch das Jordanthal südwärts.

In Richt. 5 finden wir Juda noch gar nicht $\mathrm{zu}$ den Stämmen Israel's gerechnet. Das wird seine Ursache wohl nicht haben in der Reihe kanaanitischer Städte von Jerusalem bis Philistäa. Über Jericho und durch das Transjordanische wird doch wohl Verbindung mit den Brüdern im Norden zu suchen gewesen sein. In Richt. I, I6 hat Juda noch seine Stellung um die Palmenstadt (Jericho), wo sich ihm Keniter anschliessen. Kalêb und Othniêl aus dem kenitischen Clan Kenaz werden da ausserdem als mit . Juda verbunden vorgeführt (Richt. I, I2-I 3). Soll das nicht heissen: Juda ist erst nach der Besiegung der Kanaaniter nord- und südwarts des Kisons in Kanaan eingefallen; hat in den ersten Zeiten nur die Gegend nördlich und nordöstlich von Jerusalem eingenommen; ist endlich, mit den 
aus der Kisonebene verjagten Kenitern verbunden, südwärts gerückt, und hat mit Hülfe dieser den süd-östlichen, und mit Hülfe der Reste des alten Simeonstammes den südwestlichen Teil des späteren Königreiches Juda erobert, ohne doch das starke Jerusalem unterwerfen zu können? Juda als den Ersten der alle-zugleich in Kanaan einfallenden Israeliten in Richt. I verdanken wir dem judäischen deuteronomistischen Redaktor.) In den durch Juda aufgegebenen Gegenden um Jericho breitete sich bald der schon in Barak's Tagen von Efraim getrennte Stamm Benjamin aus. Ein Eindringen der Stämme Juda und Simeon von Süden aus ist gar nicht so sicher, als z. B. Kuenen gemeint hat $(\mathrm{H}$. K. O. ${ }^{2}$ S. 356); nach der ältesten israelitischen Tradition selbst sehr unwahrscheinlich.

So können wir in Saul's Zeit die Keniter im Negeb antreffen, in Freundschaft sowohl mit Judäern als Amalekitern lebend.

Warum will Saul sie verschonen? Sie sind alte Bundesgenossen Israel's. Sie sind auch Jahwehdiener. Sie tragen das Zeichen, das sie vor Ausrottung schützt (I Mos. 4, I5), eben dasselbe Zeichen, das auch Israel trägt. Selbst von älterer Zeit her als Israel.

Eine Reminiscenz, dass Israel in der vorkanaanitischen Periode die Beschneidung noch nicht allgemein geübt hat, liefert uns $\mathrm{J}^{\mathrm{x}}$ in Jos. 5 , 2. 3. 8, obgleich uberarbeitet vom deuteronomistischen Redaktor, der die allgemeine Beschneidung in Gilgal zu 'einer wiederholten macht. Der alte Jahwist weiss es noch sehr gut, dass die Väter im Transjordanischen unbeschnitten gewesen sind, und dass die BenêMošè die Ersten in Israel waren, die das kenitische Jahwehzeichen an sich getragen haben. Wahrscheinlich ist in Gilgal, nach Inbesitznahme des alt-kanaanitischen Heiligtums, die Beschneidung feierlich eingeführt worden bei den Stämmen, 
die da kamen, Jahweh anzubeten. Juda kann, beeinflusst von den kenitischen Clans in seiner Mitte, sie bald angenommen haben. Der Name des Hügels in Gilgal (נבעת הערלות, Jos. 5, 3) deutet auf eine einstmalige Massenbeschneidung, denn dass die gewöhnliche Beschneidung je beim Heiligtume stattgefunden haben soll, und nicht immer, wie noch heute, im Geburtshause, davon findet sich nirgends im A. T. eine Spur. Was PC in I Mos. I7 erzählt von der Institution des Bundeszeichens in Abraham's Zeit ist kennbar genug Frucht theologischer Reflexion. PC konnte unmöglich die Urväter des beschnittenen Volkes, mit welchen die Geschichte Israels anfangen sollte, als mit dem heiligen Zeichen unbekannt sich vorstellen.

Ein Teil der Keniter hat vielleicht nach ihrer Vertreibung aus der Kisonebene bei den Aseritern Aufnahme gefunden, denn PC kennt einen Clan des Stammes Aser namens Heber (I Mos. 46, I7). Dieser Umstand kann auch dem Verfasser des Jabinberichtes Anleitung geboten haben, Heber vom Kison nach der Nähe von Kedes zu versetzen. Und I Chr. 2, 55 lässt den Stammvater der Rechabiter, die in Jehu's Tagen im Reiche Israel und in Jeremia's Tagen im Reiche Juda nomadisierten, kommen von Hammath (in Naphtali), wohl identisch mit 'Ammaos (Jos. Ant. XVIII, 2, 3) im heutigen Wadi Ammas, nördlich von Tiberias. Die Rechabiter können den nomadischen Sitten von Alters her treu geblieben, oder auch nach der Vertreibung des Kainstammes vom Norden dazu zurückgekehrt sein, weil sie glaubten, dass die Keniter sich durch ihre Ansiedelung auf dem Ackerland versündigt hätten.

Der kenitische Clan Kenaz, oder doch ein Teil desselben, scheint später sich Edom angeschlossen zu haben, denn PC nennt einen edomitischen Stamm Kenaz (I Mos. 36, 15). Die übrigen Keniter sind allmählich dem Juda- 
stamme einverleibt worden, und haben im Negeb Städte gebaut (I Sam. 30, 29, vergl. I Mos. 4, 17).

Habe ich hier das Richtige getroffen, dann ist eine alte crux interpretum beseitigt, und ein wenig mehr Licht gefallen auf die Geschichte des Kainstammes. Ich gebe es den Fachgenossen zur Prüfung.
's Gravenhage, Sept. I896.
H. ZEYDNER. 